\title{
Effect of Pharmacist Intervention to Self-Care Practices among Diabetes Patients
}

\author{
Syed Wasif Gillani ${ }^{1 *}$, Syed Azhar Syed Sulaiman ${ }^{1}$, Mirza Baig $^{2}$, Yelly Oktavia Sari ${ }^{3,4}$, Siti Maisharah Sheikh Ghadzi ${ }^{5}$, Sabariah Noor Haroon ${ }^{5}$
} and Nur Hafzan Md Hanafiah ${ }^{5}$

${ }^{1}$ School of Pharmaceutical Sciences, Universiti Sains Malaysia, Pulau Pinang, Malaysia

${ }^{2}$ Department of Clinical Pharmacy, Aimst University, Kedah, Malaysia

${ }^{3}$ Faculty of Pharmacy, Andalas University, Padang, Indonesia

${ }^{4}$ Discipline of Clinical Pharmacy, School of Pharmaceutical Sciences, Universiti Sains Malaysia, Penang, Malaysia

${ }^{5}$ School of Pharmaceutical Sciences, Universiti Sains Malaysia, Kubang Kerian, Kelantan, Malaysia

\begin{abstract}
Our study objective was to evaluate the pharmacist interventions in providing patient home care. A 24-week longitudinal quasi-experimental-pre-test/post-test study design was used to assess the effectiveness of a diabetes education program to enhance self-care practices. Since this was a longitudinal study a $25 \%$ attrition rate was included in the calculation of sample size. Hence the sample size for the proposed study was 106 subjects with 53 subjects in each group. All analyses were done using SPSS version $18^{\circledR}$. The level of significance was set at 0.05 The Research Ethics Committee of hospital and the Malaysian Medical Research and Ethics Committee approved the study. Of the 109 subjects who met the study-entry criteria, 3 subjects declined to participate due to lack of time and interest. There was no significant relationship between the demographic and clinical characteristic of participants who completed the study. During follow-up there was a statistically significant difference in Self Monitoring Blood Glucose (SMBG) practices between the intervention group $(M=2.94, S D=2.25)$ and control group $(M=0.47, S D=1.36$; $t(127.64)=-8.23, p \leq 0.001$ ) with moderate effect size (eta squared $=0.06$ ). Total physical activity was defined as the combination of non-leisure and leisure activities. There was a statistically significant difference in total physical levels between the intervention $(M=14.01, S D=6.41)$ and control groups $(13.21, S D=5.22 ; t(148.04)=-3.15, p=0.002)$ with no difference in the non-leisure activity $(p=0.43)$. As for the control group, there was no significant difference in $S M B G$ practices from baseline $(M=0.70, S D=1.35)$ to follow-up $(M=0.47, S D=1.36, t(72)=0.97, P=0.34)$ and no relationship was found between the number of blood glucose tests done with demographic or clinical variables. Improvement of self-care practices that require lifestyle changes such as diet and increased in physical activities are problematic. This could be due to the complexity of these self-care practices that are socially and culturally constructed and often lifetime habits when compared to SMBG.
\end{abstract}

Keywords: Diabetes mellitus; Interventional study; Longitudinal study; Pharmacist services

\section{Introduction}

Clinical practices reported that in diabetes management more therapeutic efficacy found in knowledge improvement with small effects on self-care behavior, metabolic control and psychological well-being [1]. Researcher replicated these findings with 35 additional studies which focused on the effects of different educational strategies on patient outcomes reported similar results $[1,2]$. Recent systemic reviews identified that the effectiveness of self-management training of type 2 diabetes based on randomized controlled trials also found significant findings on knowledge improvement regardless of the educational strategies used [3-5]. With regular reinforcement, knowledge level can be sustained for 24 months $[5,6]$.

Patient education appears more effective in younger patients particularly knowledge outcome [7]. No other demographic variable is reposted in relation to knowledge improvement in the meta-analysis. Whereas health literacy literature indicates older subjects, those with less education, minority ethnic groups and do not speak English are factors associated with low health literacy. These subjects often benefit less from education interventions [8-10]. The positive effects of knowledge outcomes via diabetes education must be interpreted within the methodological limitation like possible contamination due to infeasibility of participant blinding, lack of uniform measures of knowledge and the validity of the tools use $[1,4,5,8,11]$. Hence, the next question is to investigate whether the beneficial effects of education go beyond knowledge.

Majority of research reports identified moderate reduction in glycated haemoglobin with education interventions regardless of age group $[2,8,12,13]$. The glycated haemoglobin levels improve between one to six months post-intervention and the level frequently returned to baseline after six months [4-6]. Studies with follow up periods longer than one year showed mixed effects on glycaemic control [5,14-18] Since most positive studies were short-term studies, there is concern about the lack of long-term glycaemic improvement.

Education methodology appears to influence glycaemic control. Compared to didactic interventions, patient collaborative interventions produce more favorable results particularly if the interventions are repetitive and ongoing [12,19-21]. In a meta-analysis, face to face

*Corresponding author: Syed Wasif Gillani, School of Pharmaceutical Sciences, Universiti Sains Malaysia, Pulau Pinang, Malaysia, E-mail: wasifgillani@gmail.com

Received May 22, 2012; Accepted February 16, 2013; Published February 20 2013

Citation: Gillani SW, Syed Sulaiman SA, Baig M, Sari YO, Sheikh Ghadzi SM, et al. (2013) Effect of Pharmacist Intervention to Self-Care Practices among Diabetes Patients. J Diabetes Metab 4: 252. doi:10.4172/2155-6156.1000252

Copyright: (c) 2013 Gillani SW, et al. This is an open-access article distributed under the terms of the Creative Commons Attribution License, which permits unrestricted use, distribution, and reproduction in any medium, provided the original author and source are credited. 
delivery, cognitive reframing teaching and studies that included exercise content explained $44 \%$ of the variance in glycaemic control [22]. A meta-analysis reported that if require 23.6 hours of education to reduce $1 \%$ of $\mathrm{HbAlc}$ [23].

Some researchers have reported improvement of glycaemic control in both the control and study groups. In these studies, the education interventions were usually unblended [5]. In addition, lack of standardized measurements of glycated haemoglobin such as shorter than 12 week duration might not have documented the full effect of the interventions $[5,24]$.

Our study objective aimed on three clinical hypothesis; There will be no difference in medication adherence self-care practices between adults with poorly controlled diabetes who receive a structured selfefficacy education compared to those who received standard education, there will be no difference in SMBG self-care practices between adults with poorly controlled diabetes who receive a structured self-efficacy education compared to those who receive standard education, and there will be no difference in physical activities and dietary intake pattern between adults with poorly controlled diabetes who receive a structured self-efficacy education compared to those who receive standard education.

\section{Methodology}

\section{Research design}

The purpose of this study was to examine the effect of an intervention. For logistical reason, this study was necessarily a small one and had to be completed within the study period. A 24-week longitudinal quasi-experimental - pre-test/post-test study design was used to assess the effectiveness of a diabetes education program to enhance self-care practices [25]. A double-blinded randomized study design was considered but was not feasible as the investigator was responsible for implementing the intervention and collecting data on outcomes $[25,26]$.

\section{Theoretical framework}

Findings from literature reviews have shown the importance of incorporating behavioral theories in Diabetes Self-management Education interventions because they provide an understanding of the cognitive and psychosocial processes that influence health decisionmaking and behavior. Self-efficacy has been shown to act as the mediating link between cognitive preparation (knowledge and skill) and actual task engagement [27-29]. Furthermore, when comparing self-efficacy to other psychosocial interventions, self-efficacy emerged as better predictor of self-care diet intake, exercise and blood glucose monitoring. It shared $4 \%$ to $26 \%$ of variance of self-care behavior when compared to Health Belief Model, outcome expectancies, autonomous self-regulation and social support in both Type 1 and Type 2 diabetes [27-29]. Hence self-efficacy in-home care practice was the choice of theoretical framework for this study.

\section{Subjects}

Inclusion criteria: Subjects were included if they

- Were non-pregnant adults $>18$ years of age regardless of gender or ethnicity

- Had diabetes for more than a year

- Spoke and understood Bahasa Malaysia, English, Mandarin or Chinese dialects (Cantonese, Hokkien or Teow-chew) as these were the languages used during the pre-and post-assessments and education interventions

- Had a medical record showing poor diabetes control ${ }^{*}$

*Poor diabetes control in this study was defined as HbAlc of more than $7 \%$ for two reasons. First the currently global recommended glycaemic target measured by HbAlc is between $\leq 6.5 \%$ to $\leq 7 \%$. Second, empirical studies reported that HbAlc of more than $7 \%$ is associated with increased micro-vascular complications [30-32].

Exclusion criteria: Subjects were excluded from the study if they

- Were above 18 years of age but unable to answer the questionnaire independently due to mental illness, senility, other co-morbidities, unstable medical condition such as inpatients

- Had hearing impairment as they might have had problems with telephone follow-ups for education and data collection

- Had vision impairment as they might not be able to assess the portion size of their carbohydrate intake or prescribed medication

- Were pregnant women with diabetes or diagnosed with gestational diabetes due to the different criteria on standard of control

Sample size: The required sample size was calculated with a power analysis using the procedure provided by Polit and Hungler [33]. Selfcare practice was the primary outcome. The power was set at 0.7 with an alpha of 0.05 . The investigator was unable to calculate the effect size using previous studies as there are no previous studies that measure the four self-care practices together. Hence the convention developed by Cohen (1988 cited in Polit and Hungler) was used (p492) [33]. Based on this, the value of effect size in a two-group test of mean difference was estimated at $0.20-0.49$ for small effect, $0.50-0.79$ for medium effect and 0.80 for large effect. To test for a significant difference between the two groups, a medium effect size of Gamma 0.5 was arbitrarily adopted, requiring a sample size of 42 in each group or a total of 84 Since this was a longitudinal study a $25 \%$ attrition rate was included in the calculation of sample size. Hence the sample size for the proposed study was 106 subjects with 53 subjects in each group.

Setting: One hundred and sixty subjects with poor diabetes control were recruited from the general medical outpatient's clinics of general hospital in the state of Penang. A general hospital was defined as the main government hospital in the state offering tertiary care. Subjects were not recruited from the private clinics and hospitals for reasons of possible demographic and psychosocial differences which could affect the intervention outcomes. Cases were intervening in their respective homes while controls were observed in the usual appointments at outpatient department of the hospital.

\section{Research tools}

Physical activity self-care: The assessment of physical activity included items from both non-leisure physical activities like occupational-/housework-/college-related activities (4 items) and leisure activities ( 7 items). Based on the findings of the previous study, to enhance clarity, the activities level was assessed using a 5 -point Likert scale with ' 1 ' indicating 'never' and ' 5 ' indicating 'all the times' from questions one to seven. (For questions 1 and 7, the score are reversed). Questions 8 to 11 assess the frequency, intensity and duration of the leisure activity during the preceding week. The total 
score was calculated for both leisure and non-leisure physical activities. In each category, the levels of activities were defined as 'least active', 'moderately active' and most active' according to the score achieved (Table 1).

Self-monitoring of blood glucose practice: At baseline, subjects were asked questions about the recommended weekly frequency of self-monitoring. No score was allocated for recommended frequency. The frequency of SMBG and treatment modification was assessed using a 9-point scale from ' 0 ' to more than 7 times'. Timing of SMBG was assessed using an 8-point scale from ' 0 ' to ' 7 '. The scoring system was based on the frequency of SMBG and treatment modification done during the preceding week (questions 4,8-10). Although previous studies unanimously recognized the importance of SMBG in diabetes management, there were discrepancies between the recommended frequency and timing of SMBG [34-36]. Previous researchers reported less than $25 \%$ of Malaysians with diabetes practiced SMBG $[37,38]$. Hence for the purposes of this study, a minimum of four blood glucose testing in the preceding week was considered as adequate SMBG selfcare practice.

Dietary intake: Dietary intake behavior was assessed at baseline and after the intervention using two methods. First, a 24-hour dietary recall in which researcher ask about the last 24-hour food intake during the study. Second, a culturally appropriate Food Frequency Questionnaire (FFQ) developed by the investigator.

24-hours dietary recall: The first 24-hour dietary recall was recorded during the baseline interview. The second 24-hour dietary recall was done by telephone interview within 7 days of the first interview. At the end, the first 24-hour dietary recall was recorded the week before their last appointment. The last 24 -hour dietary recall was done during the $24^{\text {th }}$ week appointment day.

Food frequency questionnaire: The FFQ contained 100 food items commonly consumed in Malaysia diet to identify the daily and episodic carbohydrate consumption during the preceding week. The list of food items was derived from the daily dietary intake of 145 food records collected in the previous study and the pilot study. The portion sizes of the FFQ were divided into small, medium and large of which small $=0.5 \mathrm{X}$ standard $/$ medium portion size, medium $=1 \mathrm{X}$ medium portion size and large $=1 \mathrm{X} 1.5 \mathrm{standard} /$ medium portion size. The medium portion is the common household measurements converted into food weights in grams based on local food [39]. To enhance precision, the investigator weighted some commonly consumed food items. In addition, the manufacturers' data were also used for some processed foods that were not listed in the local food references.

Dietary assessment: Adherence to dietary self-care was assessed by the quantity and frequency of carbohydrate intake in relation to subjects' $\mathrm{HbAlc}$ results. It also assessed intake of protein, fat and total calories per day. A ratio of reported energy intake to basal metabolic rate (EI: BMR) is used as guide to assess the accuracy of self-reported food recorded in this study. The formula for calculating of EI: BMR for the study subjects is based on a previous study with Malaysian people [40].

Post-questionnaire: The post-questionnaire (59 items) was the same as the pre-questionnaire but excluding demographic data, previous glycaemic control and recommendations for SMBG. The sequence of the 20-item diabetes knowledge assessment session was re-arranged to minimize the effect of learning from the previous questionnaire. All scoring systems remained the same. It was administered to all subjects at the $24 \pm 2$ weeks during follow-up identify any difference in knowledge and the four self-care practices between groups and within groups.

Ethical consideration: The Research Ethics Committee of hospital and the Malaysian Medical Research and Ethics Committee approved the study.

\section{Statistical analysis}

Demographic data was analyzed using descriptive statistics. A 2-tailed t-test was used to analyze any difference between the intervention and control groups and within groups for ratio data such as medication adherence rate. Chi-square was used to analyze the relationship between nominal data such as gender. Multiple regressions were performed to predict the variance of different self-care practices after the education with post-HbAlc levels. All analyses were done using SPSS version $18^{\circ}$. The level of significance was set at 0.05 .

\section{Results}

Of the 109 subject who met the study-entry criteria, 3 subjects declined to participate due to lack of time and interest. One hundred and six subjects were randomized to either control or intervention group with 53 subjects in each group. Thirteen subjects withdrew from the study for reasons of lack of interest $(n=9)$, transferred to either healthcare centre $(n=20)$, severe anaemia and hence were unable to read the post-HbAlc $(n=1)$ and one died. The primary result of this study were based on data from the 93 subject who completed the 24 -weeks (6 months) follow-up (intervention=47, control=46).

\section{Self-Monitoring of blood glucose self-care [SMBG]}

During follow-up there was a statistically significant difference in SMBG practices between the intervention group $(\mathrm{M}=2.94, \mathrm{SD}=2.25)$ and control group $(\mathrm{M}=0.47, \mathrm{SD}=1.36 ; \mathrm{t}(127.64)=-8.23, \mathrm{p} \leq 0.001)$ with moderate effect size (eta squared $=0.06$ ).

Within the intervention group, not all the subjects monitored their SMBG four times a week as instructed. During the 24 weeks

\begin{tabular}{|c|c|c|c|}
\hline Types of physical activity & Category of activity & Definition of category of physical activity & Activity Score \\
\hline \multirow[t]{3}{*}{ Non- Leisure activity } & Least active & Almost all the time sitting, seldom standing, walking, or carrying heavy things & $0-5$ \\
\hline & Moderately active & Sometimes sitting, standing, walking or carrying heavy things. & $6-11$ \\
\hline & Most active & $\begin{array}{l}\text { Almost none of the time sitting, almost all the time standing or walking, most of the time carry } \\
\text { heavy things. }\end{array}$ & $12-16$ \\
\hline \multirow[t]{3}{*}{ Leisure activity } & Least active & $\begin{array}{l}\text { Never or seldom walk around the house or gardening. Most of the time sitting down. No regular } \\
\text { exercise program }\end{array}$ & $0-6$ \\
\hline & Moderately active & $\begin{array}{l}\text { Sometimes gardening, walking around the house, sitting down to watch TV. Inconsistent exercise } \\
\text { program with minimum intensity }\end{array}$ & $7-16$ \\
\hline & Most active & $\begin{array}{l}\text { Most of the time walking around the house, gardening and seldom sit down. Exercise regularly } \\
\text { with moderate intensity on } 5 \text { or more days a week with more than } 30 \text { minutes each session }\end{array}$ & $17-28$ \\
\hline
\end{tabular}

Table 1: Category of physical activity levels. 
Citation: Gillani SW, Syed Sulaiman SA, Baig M, Sari YO, Sheikh Ghadzi SM, et al. (2013) Effect of Pharmacist Intervention to Self-Care Practices among Diabetes Patients. J Diabetes Metab 4: 252. doi:10.4172/2155-6156.1000252

the mean number of times this was done was $2.94(\mathrm{SD}=2.25)$ ranging between 0-8 test per week. Despite the inconsistent practices, there was a statistically significant difference in SMBG practices from baseline $(\mathrm{M}=0.60, \mathrm{SD}=1.39)$ to follow-up $(\mathrm{M} 2.94, \mathrm{SD}=2.25, \mathrm{t} 977)=-8.73, \mathrm{p} \leq$ 0.001 ) with large effect size (eta squared $=0.32$ ). In addition, there was a significant relationship between total number of SMBG performed and $\mathrm{HbA1c}$ result $(\mathrm{r}=-0.25, \mathrm{p}=0.03)$, carbohydrate intake $(\mathrm{r}=-0.24, \mathrm{p}=0.04)$ and medication adherence practices $(\mathrm{r}=+0.27, \mathrm{p}=0.03)$. There was no relationship between $S M B G$ practices with demographic data or postknowledge assessment or level of physical activity.

As for the control group, there was no significant difference in SMBG practices from baseline $(\mathrm{M}=0.70, \mathrm{SD}=1.35)$ to follow-up $(\mathrm{M}=0.47, \mathrm{SD}=1.36, \mathrm{t}(72)=0.97, \mathrm{P}=0.34)$ and no relationship was found between the number of blood glucose tests done with demographic or clinical variables.

\section{Physical activity self-care}

Total physical activity was defined as the combination of nonleisure and leisure activities.

There was a statistically significant difference in total physical levels between the intervention $(\mathrm{M}=14.01, \mathrm{SD}=6.41)$ and control groups (13.21, $\mathrm{SD}=5.22 ; \mathrm{t}(148.04)=-3.15, \mathrm{p}=0.002)$ with no difference in the non-leisure activity $(\mathrm{p}=0.43)$.

After education, the intervention group showed slight improvement in total, non-leisure and leisure activity but this was not significant. As for the control group there was no difference in all level of physical activities with deterioration in total activity level from baseline (Figures 1-3), compared the frequency of all activity levels of the intervention and control groups at baselines and $24^{\text {th }}$ week. No significant relationship was found between demographic or clinical variables, post-knowledge assessment and post-HbA1c level with subject's physical activity levels.

\section{Dietary self-care}

Total daily carbohydrate intake in grams was assessed using the FFQ and 24-hour dietary recall. Twenty-four-hour dietary intake was analyzed using the Nutritionist pro version 2.0, First databank, USA. Based on the Wilcoxon Signed Rank Test, there was significant difference between the agreement of the two assessment tools $(Z=-4.18$, $p \leq 0.001)$. Due to significant differences in the FFQ result and those of the 24-hour diet recall data for several reasons. First, 24-hour diet recall documented the subject's actual previous day's intake. The FFQ

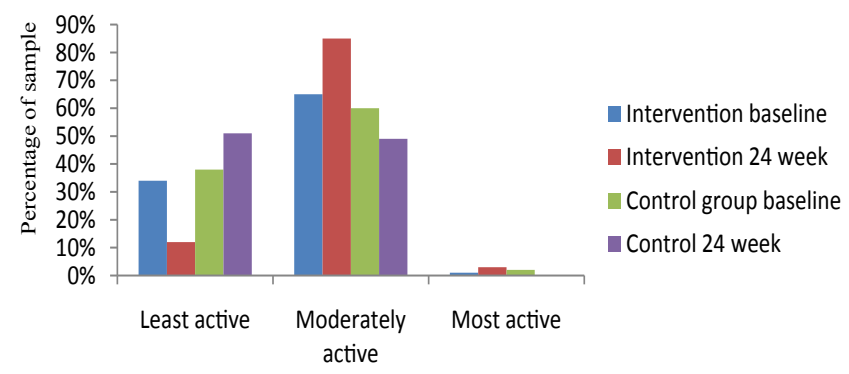

Category of Activity

Note: There was no significance between the frequency of non-leisure activity levels from baseline and $24^{\text {th }}$ week for both the intervention and control groups

Figure 1: Frequency of of non-leisure activity at baseline and $24^{\text {th }}$ week.

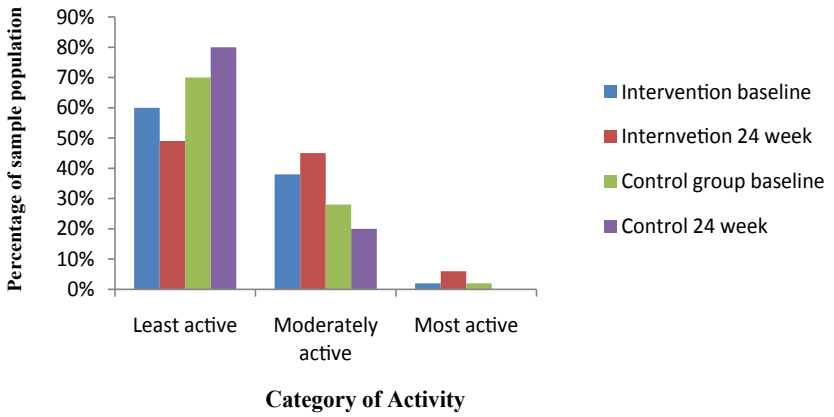

Note: There was a significant difference in frequency of leisure activity between the intervention and control group at the $24^{\text {th }}$ week. However, within both the intervention and control groups, there was no significant difference regarding the frequency of leisure activity levels from baseline and $24^{\text {th }}$ week

Figure 2: Frequency of leisure activity levels at baseline and $24^{\text {th }}$ week.

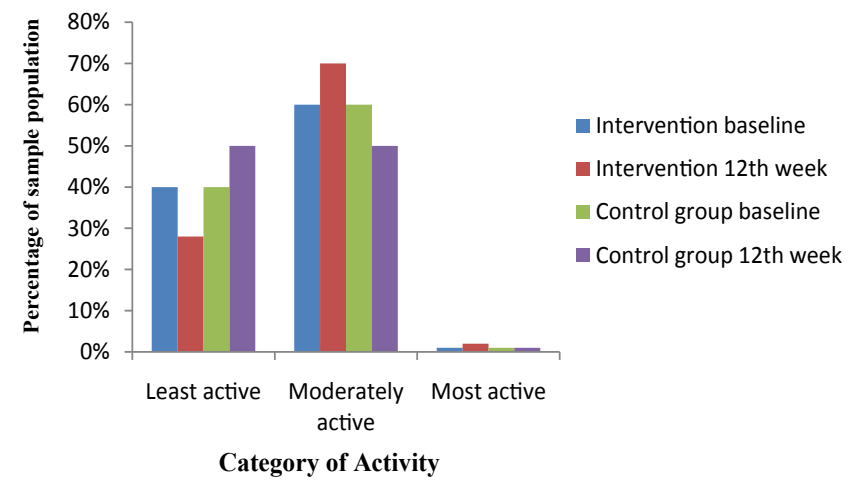

Note: There was a statistically significant difference in frequency of tota physical activity levels between the intervention and control group at $24^{\text {th }}$ week. However, within both the intervention and control groups, there was no significant difference regarding frequency of total physical activity levels from baseline and $24^{\text {th }}$ week

Figure 3: Frequency of total physical activity levels at baseline and $24^{\text {th }}$ week.

provided an overview of habitual food intake over the previous week which might not necessarily had been actually taken by the subjects in reality. It might have overestimated the intake especially when a large number of foods were listed. Furthermore the consistency with assessment of total daily calories, protein, fat and sugar intake which were derived from the 24-hour diet recall data was taken into account.

At week 24, there was a significant difference in the 24-hour dietary recall between the intervention and control groups in total daily calorie, carbohydrate, protein, fat and sugar intake (Tables 2 and 3).

In the intervention group there was statistically significant reduction in daily total caloric intake from baseline $(\mathrm{M}=1732, \mathrm{SD}=455)$ to followup $(\mathrm{M}=1179, \mathrm{SD}=376 ; \mathrm{t} 9(2.66) \mathrm{df}=77, \mathrm{p}=0.021)$; protein intake from baseline $(M=67, S D=25)$ to follow-up $(M=59, S D=15 ; t(2.77) d f=77$, $\mathrm{p}=0.01$ ). There was slight reduction carbohydrate and sugar intake between baseline and follow-up.

\section{Demographic data and dietary self-care}

Male subjects (mean $1750+515$ kilocalories) consumed more calories daily than female subjects (mean $1530+401$ kilocalorie; Mann- 
Citation: Gillani SW, Syed Sulaiman SA, Baig M, Sari YO, Sheikh Ghadzi SM, et al. (2013) Effect of Pharmacist Intervention to Self-Care Practices among Diabetes Patients. J Diabetes Metab 4: 252. doi:10.4172/2155-6156.1000252

Page 5 of 9

\begin{tabular}{|c|c|c|c|c|c|c|}
\hline Food composition & Interventic & nean [SD] & Control g & iean [SD] & $\mathbf{t}$ & $P$ value \\
\hline Totally daily calorie [kilocalories] & 1179 & [376] & 1663 & [418] & 1.28 & 0.02 \\
\hline Carbohydrate [gram] & 211 & [60] & 252 & [63] & 1.58 & 0.01 \\
\hline Protein [gram] & 59 & [18] & 61 & [18] & 0.56 & 0.07 \\
\hline Fat [gram] & 36 & {$[15]$} & 47 & [21] & 0.6 & 0.05 \\
\hline Sugar [gram] & 18 & [18] & 29 & [22] & 1.79 & 0.01 \\
\hline
\end{tabular}

Table 2: Comparison : Comparison of 24-hour Dietary Intake between the Intervention and the Control Group at $24^{\text {th }}$ week [n $=93$ ].

\begin{tabular}{|c|c|c|c|c|c|c|}
\hline \multirow{3}{*}{$\begin{array}{l}\text { Food composition } \\
\text { Totally daily calorie [kilocalories] }\end{array}$} & \multicolumn{4}{|c|}{ Intervention Group } & \multirow{3}{*}{$\begin{array}{c}\mathbf{t} \\
2.66\end{array}$} & \multirow{3}{*}{$\begin{array}{l}\text { P value } \\
0.001^{*}\end{array}$} \\
\hline & \multicolumn{2}{|c|}{ Baseline Mean [SD] } & \multicolumn{2}{|c|}{ Week 24 Mean [SD] } & & \\
\hline & 1732 & {$[455]$} & 1179 & [376] & & \\
\hline Carbohydrate [gram] & 246 & {$[64]$} & 211 & {$[60]$} & 1.26 & 0.025 \\
\hline Protein [gram] & 67 & [25] & 59 & [18] & 2.55 & $0.010^{*}$ \\
\hline Fat [gram] & 52 & [22] & 36 & [15] & 2.77 & $0.014^{*}$ \\
\hline Sugar [gram] & 24 & [16] & 18 & [18] & 0.57 & 0.051 \\
\hline
\end{tabular}

${ }^{*} p<0.05$

Table 3: Comparison of 24-hour dietary intake of the intervention group from baseline to $24^{\text {th }}$ week [n $=93$ ]

Whitney $\mathrm{U}, \mathrm{p}=<0.001)$. The fieldworkers consumed the highest daily calories (mean $1950+350$ kilocalories) with the least being consumed by housewives (mean $1473+283$ kilocalories; $\mathrm{x}^{2}=13.96, \mathrm{df}=5, \mathrm{p}=0.02$ ).

Both male and female Malay subjects had the highest sugar intake (mean $29+19 \mathrm{~g}$ ) with the Chinese consuming the least (mean $19+15$ $\mathrm{g}, \mathrm{x}^{2}=9.18, \mathrm{df}=3, \mathrm{p}=0.03$ ). These findings were supported by the Malay subjects having the heaviest body weights $(\mathrm{p}=0.004)$, highest BMI $(\mathrm{p}=<0.001)$ and largest waist circumferences $(\mathrm{p}=0.01)$. No relationship was found between carbohydrate and total daily calorie intakes with other demographic or clinical variables.

Goldberg et al. and Black reported a ratio of basal metabolic rate (EI: BMR) below 1.2 is usually regarded as an energy intake too low for the maintenance of body weight [41,42]. In this study, $57 \%$ of intervention subjects and $54 \%$ of control subjects had an EI: BMR ratio below 1.2 which might indicate possible under-reporting of their 24hour dietary intake.

\section{Discussion}

\section{Self-Monitoring blood glucose practices}

Ho1: There will be no difference in SMBG self-care practices between adults with poorly controlled diabetes who receive a structured self-efficacy education compared to those who receive standard education.

There was a significant difference between the intervention and control group SMBG practices and therefore the null hypothesis was rejected. The improvement in SMBG self-care in the intervention group was anticipated not only because of the education intervention, but also because the subjects were provided with free test strips. Due to limited supply of free test strips, the advised frequency of monitoring was not based on the current recommendation of 2-3 times per day for insulin users and minimum once a day for those with OAM [43]. Instead all the intervention subjects were advised to practice SMBG between 3-6 times per week. Despite the free supply of blood glucose test strips, there was substantial variation between 0-8 times of monitoring per week with a mean of $2.94(\mathrm{SD}=2.25)$ times per week. Since cost was not a barrier for SMBG among the Intervention subjects, infrequent occurred for other reasons. Previous studies had cited these being: attitude toward SMBG, lifestyle interference, inconvenience, pain, old age and cost [44-46]. These barriers were not investigated in this study and should be explored in the future. Thus this finding only partially supported the assumption of this study that people with diabetes when provided with the opportunity to practice SMBG would improve their self-care practices.

The lack of change in the SMBG practices in the control group mirrored results from the first study of this portfolio [47]. As explained earlier, Malaysian engages in social medicine where the government heavily subsides the cost of medication for patients attending government-run healthcare facilities [46]. The government however does not finance the cost of SMBG. This could act as a financial to SMBG self-care especially for patients from lower socio-economic backgrounds.

Although it was the purpose of this study to encourage SMBG selfcare, so at the end of the study the intervention subjects were given incentive by investigator, blood glucose monitoring meter. Sixty-four percent of the intervention subjects regardless of age, level of education and types of diabetes continued to practice SMBG after study. This is an important observation which reflected the acceptance of SMBG practices and treatment satisfaction by individuals in the intervention group.

Earlier researcher have reported conflicting findings on the efficacy of SMBG among Type 2 diabetic subjects, especially those prescribed with OAM $[39,48,49]$. In this study the intervention group comprised $95 \%$ of Type 2 diabetic of which $78 \%$ were prescribed on OAM and combination therapy. These subjects had lower HbAlc levels compared to the control group. This could be due to more frequent SMBG practices enhancing intervention subject's medication adherence. In addition, there was also a significant relationship between total number SMBG performed and $\mathrm{HbAlc}$ result $(\mathrm{p}=0.030$ and carbohydrate intake $(p=0.04)$. The findings of this study are consistent with previous research reporting a negative correlation between frequency of SMBG with HbA1c levels [50,51]. The increased frequency of SMBG had enhanced the self-care practices of the intervention group in dietary and medication intake.

Previous study found improved Hb1Ac levels with self-adjustment of insulin dosage [52,53]. However, in this study, increases in medication dosage by the attending doctors didn't lower the HbAlc of the intervention group $(\mathrm{p}=0.57)$.

Instead the intervention subjects were shown on meal-related SMBG to identify excessive carbohydrate intake. It was explained to the subjects that the same meal, if there was a difference between 
the pre-meal and the 2-hour post-meal blood glucose levels greater than $4 \mathrm{mmol} / \mathrm{L}$, it might indicate excessive carbohydrate intake for that particular meal. For example, if the pre-meal blood glucose was $8 \mathrm{mmol} / \mathrm{L}$ and 2 hour later, the blood glucose level was $16 \mathrm{mmol} / \mathrm{L}$, there could be due to excessive carbohydrate intake for that particular meal. However, if the pre-meal blood glucose was $14 \mathrm{mmol} / \mathrm{L}$ and 2 hours later, the blood glucose level was $16 \mathrm{mmol} / \mathrm{L}$, the post-prandial hyperglycaemia might not be due to intake of food but other causes. To increase their self-efficacy in dietary management, they were then guided to identify the carbohydrate food items in the meal so as to reduce the carbohydrate intake in the future. At the end of this study, subjects who practiced more frequent meal related SMBG reduced their carbohydrate intake $[\mathrm{p}=0.04]$. Similar findings have been reported in previous studies $[54,55]$. Furthermore, it was also explained that persistent fasting hyperglycaemia might be due to medication nonadherence and wrong timing of medication intake. With self-efficacy education the intervention group improved its medication intake practices ( $\mathrm{p}=0.03)$. The above findings had supported the assumption of this study which argued the beneficial effects of SMBG with treatment modifications.

\section{Physical activity self-care}

Ho2: There will be no difference in physical activity self-care practices between adults with poorly controlled diabetes who received a structured elf-efficacy education compared to those who received standard education.

There was a significant difference in physical activity self-care practices between the intervention and control groups and therefore the null hypothesis was rejected. However this finding has to be interpreted with caution, the small difference in physical activity levels between the groups and absence of significant improvement in within group comparison may be due to several in Malaysia.

Twenty-seven percent of the subjects were either factory or field workers. These subjects frequently reported lack of time as a problem in engaging in regular exercise. In Addition, they also perceived they had done enough activity during their working hours [between 8 to 12 hours per day for six to seven days a week]. Previous researchers have reported similar results among Asian people of lower social economic status [56,57]. Females comprised $60 \%$ of the intervention group of which $84 \%$ were housewives. Previous studies frequently reported that females were less active than males especially in regular exercise programs due to cultural expectations that they do household and childcare activities [58-60]. This might explain the finding of the small difference in non-leisure physical activity between the groups.

Thirty-six percent of this study subjects were Malay females. One previous study done Malaysia reported that in general, Malay Muslim women were socially conditioned to act in groups [61]. If there was lack of family support, this could act as barriers to exercise which has been reported. $[56,60,61]$ In addition, exercise facilities such as parks or sport centers are not easily accessible as some form of transportation is often necessary to reach such community establishments. In this study, female constituted on group that had problems with transportation $(\mathrm{p}=0.04)$.

The incidence of 'snatch theft' in Malaysia has increased during the last few years and contributed to unsafe environment especially for females exercising alone outdoors [62,63]. Due to lack of local sport facilities, walking around the house compound was frequently encouraged. However, walking for obese subjects involved a high degree of effort and pain [64]. This might explain the low exercise adherence since $40 \%$ the study population had BMI of more than 30 .

According to Bandura's theory of self-efficacy, performance expectations predict whether an individual will choose to engage in a behavior [37]. In this study, to encourage achievable goal and behavior change, the goals were usually set by the subjects. Despite providing an explanation and encouragement to exercise, most of the subjects chose to set their immediate goals related to diet and SMBG rather than exercise. The outcome of this was improvement in their dietary knowledge compared to know regarding exercise.

Only five percent of the intervention subjects increased their leisure physical activity levels from baseline after intervention. The result was consistent with the Malaysian Non-communicable Disease Surveillance done in 2006, which reported $60 \%$ of Malaysian adults between 25-64 years were physically inactive [65]. Barriers to exercise and the underlining reasons for not setting exercise goals during the education sessions were not explored in this study. Importantly, further research on this theme is necessary to overcome the problem of in activity in Malaysia.

There are two possible explanations for the lack of change in $\mathrm{HbAlc}$ levels despite increased physical activity of the intervention group. First, there was only a small increment in overall physical activities among intervention subjects. Second, those subjects with regular exercise programs or during their non-leisure physical activities did not achieve the duration and in intensity of physical activity levels as recommended for people with diabetes. To benefit from physical activity, people with diabetes need to perform a minimum if 150 minutes per week of moderately intense aerobic intense aerobic physical activity which is equivalent to achieving $50 \%-70 \%$ of maximum heart rate. 199 Hence although the alternate hypothesis of physical activity was supported, it had little clinical implication.

\section{Diet self-care}

Ho3: There will be no difference in dietary self-care practices between adults with poorly controlled diabetes who receive a structured self-efficacy education compared to those who receive standard education.

This result showed no difference in dietary self-care practices between the intervention and control groups which support the null hypothesis. However, for the within group comparison the intervention group showed significant reduction from baseline to week 24 in daily total calorie, protein, and fat intakes. The lack of significant difference between groups may have several explanations. Firstly, due to lack of data on variance, a medium size effect was arbitrarily chosen which could have resulted in the sample size not being big enough. Secondly, the instrument was not sensitive enough to detect any difference. Thirdly, factors other than or in addition to diabetes education are needed to make a bigger difference in order to demonstrate a difference between groups. Lastly, the Malaysian setting can be an influencing factor. This is explained in more detail below.

Underreporting of food intake is a well known phenomenon and the prevalence varies with the method used, ranging from $22.2 \%$ to $66.7 \%$ [66-68]. In this study, the self-reported low energy intake was compared to the subjects' basal metabolic rate and appears to suggest this had occurred. One previous study assessing the nutrient intakes of adult Pakistani, European and African-Caribbean communities of an inner city in Britain reported that the European participants were least likely to underreport their dietary intake. The author explained 
that cultural influence, food habits and missing data from the food composition tables were potential factors for the Pakistanis who had the highest underreporting rate [68]. In Asian cultures, foods are usually served in common dishes rather than individual servings. Hence assessing portion sizes can be difficult. Obtaining accurate reports for foods eaten in mixed dishes was problematic. Although the food composition analysis software, Nutritionist Pro, has included a Malaysian food composition table, the information available on specific local ethnic foods is limited. This could be due to the fact that the last edition of the Malaysian food composition table was updated in 1997 [69]. All the above factors could have contributed to the possible underreporting in this study. Similar to previous studies, it was also observed that subjects with higher BMI and waist circumference in this study more often self-reported as taking less dietary intake [70-72].

Despite increased dietary knowledge and setting dietary goals during the education sessions, reduction of carbohydrate and sugar intake was not significant among the subjects in the intervention group. There could be several possible explanations for this finding. Even though it was planned, few intervention subjects were taught about carbohydrate counting because of their low dietary knowledge. Only $11 \%$ of the intervention subjects could identify sources of common daily carbohydrate food items at baseline. Hence the objective of the dietary education was changed to enhance the subjects' dietary knowledge on sources of carbohydrate food. Reducing carbohydrate portion sizes was done subjectively rather than objectively.

Dietary self-care is constantly influenced by social, cultural, religious and environment contexts than can make changing eating habits more difficult when compared with self-care practices $[60,64,73,74]$. It is a local practice especially among families of a lower social economic status to prepare family beverages and food in common servings rather than individual servings. If there was a lack of family support or understanding about the importance of dietary self-care in diabetes management, individual dietary behavior would become a problem due to family members, dietary preferences and food preparation. This was illustrated in a qualitative study of older Hispanic adults with Type 2 diabetes $(n=138)$ which reported the most difficult issue was being around with people who are eating or drinking things that they should not take [75]. Although family support related to dietary intake was not explored in this study, $82 \%$ of subjects in this study were married and live with family members. This could have contributed to a minimal reduction in carbohydrate intake quantities compared to base line.

Furthermore in this study $40 \%$ of the subjects were males and $82 \%$ were married. The family members who prepared the family meals did not accompany subjects to education sessions despite being encourage to do so. This could act as a barrier to dietary self-care for the male subjects as reported in previous studies [64,73]. Further research should be conducted to see if including families in clinic visits does, in fact, improve dietary adherence.

Dietary modifications often require individuals with diabetes to alter the behavior of a lifetime which are used upon strong and entrenched preference. In this study, Malays consumed the most sugar $(\mathrm{p}=0.03)$. This finding is supported by previous studies that explored dietary habits of the Malay population in Malaysia [76-78]. In one study, $27 \%$ of subjects had morning or afternoon snacks every day or almost every day besides their main meal. The subjects in that same study regularly consumed biscuits, traditional sweet cakes, condensed milk or sugar in their daily beverages. Although sugar or sucrose is allowed in a daily diet to a maximum of $10 \%$ of total calories, it needs to replace other carbohydrates [79-81]. It was uncertain whether the subjects in the intervention of sucrose intake with their staple diet-rice or noodles.

Sixty percent of the subjects in this study were Malays. This factor may contribute to the findings regarding insignificant reduction of carbohydrate intake. This finding has public health implications as the Malay subjects with habitual sugar intake were also more likely to have higher BMI and waist circumference $(\mathrm{p}=0.01)$. Malays constitute $65 \%$ of factors for developing diabetes mellitus and contribute to poor glycaemic control among the diabetics $[82,83]$. Previous studies that found positive dietary interventions usually involved more than six hours of dietary intervention with continuous reinforcement $[84,85]$. In this study, the mean education intervention lasted 97 minutes to address all four self-care practices. This could have contributed to the insignificant findings.

As reported earlier, meal-related SMBG was shown to reduce carbohydrate intake. The frequency of SMBG among the intervention subjects, however, was inconsistent which could have contributed to the small reduction in carbohydrate intake. Nevertheless, in the intervention group, there was reduction in total daily caloric consumption after the education as compared the control group. The reduction in daily caloric intake was contributed to by reduction in fat and protein intake. $(\mathrm{p}=0.01)$. A reduced fat intake may reduce serum lipids and modify a major risk factor for cardiovascular complications in diabetes [86-88]. Hence a reduction in fat intake reflects good selfcare practices.

\section{Conclusion}

Patient home-care program (PHCP) has shown a brief structured education program that incorporated behavior science specifically selfefficacy was effective in enhancing the self-care practices (SMBG) in the intervention group. Improvement of self-care practices that require lifestyle changes such as diet and increased in physical activities are problematic. This could be due to the complexity of these self-care practices that are socially and culturally constructed and often lifetime habits when compared to SMBG.

\section{Authors' Contributions}

All these authors contributed equally to this work.

\section{Acknowledgements and Funding}

We would like to acknowledge all patients who actively involved in this research work. We would also like to appreciate the nursing staff of out-patient department for assistance in the administrative work in the patient selection and enrollment.

\section{References}

1. Ponte C (1996) Non-insulin-dependent diabetes mellitus --current practice and future trends. JAm Pharm Assoc (Wash) 36: 50-58.

2. Mensing C, Boucher J, Cypress M, Weinger K, Mulcaby K, et al. (2000) Nationa standards for diabetes self-management education. Task Force to Review and Revise the National Standards for Diabetes Self-Management Education Programs. Diabetes Care 23: 682-689.

3. Parving $\mathrm{HH}$, Lehnert $\mathrm{H}$, Bröchner-Mortensen J, Gomis R, Andersen S, et al (2001) The effect of irbesartan on the development of diabetic nephropathy in patients with type 2 diabetes. N Engl J Med 345: 870-880.

4. Foreyt JP, Poston WS 2nd (1999) The challenge of diet, exercise and lifestyle modification in the management of the obese diabetic patient. Int $\mathrm{J}$ Obes Relat Metab Disord 23: S5-S1 1.

5. Baliga BS, Fonseca VA (1997) Recent advances in the treatment of type II diabetes mellitus. Am Fam Phys 55: 817-824.

6. Bailey CJ, Turner RC (1996) Metformin. New Engi JMed 334: 574-579. 
Citation: Gillani SW, Syed Sulaiman SA, Baig M, Sari YO, Sheikh Ghadzi SM, et al. (2013) Effect of Pharmacist Intervention to Self-Care Practices among Diabetes Patients. J Diabetes Metab 4: 252. doi:10.4172/2155-6156.1000252

7. Mann JF (2000) Should the results of the HOPE study affect nephrological practice? For the HOPE investigators. Nephrol Dial Transplant 15: 453-454.

8. Stang M, Wysowski DK, Butler-Jones D (1999) Incidence of lactic acidosis in metformin users. Diabetes Care 22: 925-927.

9. Anonymous (2003) Schedule of Pharmaceutical Benefits. In. February 2003 ed: Department of Health and Ageing; www.hic.gov.au.

10. Whittemore $R$ (2000) Strategies to facilitate lifestyle change associated with diabetes mellitus. J Nurs Scholarsh 32: 225-232.

11. Wing RR, Anglin K (1996) Effectiveness of a behavioral weight control program for blacks and whites with NIDDM. Diabetes Care 19: 409-413.

12. DeFronzo RA (1999) Pharmacologic therapy for type 2 diabetes mellitus. Ann Intern Med 131: 281-303.

13. Wen LK, Shepherd MD, Parchaman ML (2004) Family support, diet, and exercise among older Mexican Americans with type 2 diabetes. Diabetes Educ 30: $980-993$.

14. Savoca MR, Miller CK, Quandt SA (2004) Profiles of people with type 2 diabetes mellitus. The extremes of glycaemic control. Soc Sci Med 58: 2655-2666.

15. Turner R, Cull C, Holman R (1996) United Kingdom Prospective Diabetes Study 17: a 9- year update of a randomized, controlled trial on the effect of improved metabolic control on complications in non-insulin-dependent diabetes mellitus. Ann Intern Med 124: 136-145.

16. Arc A, Korhonen T, Halinen M (1978) Phenformin-induced lactic acidosis precipitated by tetracycline. Lancet 1: 673-674

17. Somogyi A, Stockley C, Keal J, Rolan P, Bockner F (1 987) Reduction of metformin renal tubular secretion by cimetidine in man. Br J Clin Pharmacol 23: 545-55 1.

18. Lubbos H, Miller JL, Rose LI (1995) Oral hypoglycemic agents in type II diabetes mellitus. Am Fam Physician 52: 2075-2078.

19. Yeap BB (2001) Primary care diabetes. what options are there? Aust Fam Phys 30: $1122-1128$

20. Kubacka RT, Antal EJ, Juhi RP, Weishman IR (1 996) Effects of aspirin and ibuprofen on the pharmacokinetics and pharmacodynamics of glyburide in healthy subjects. Ann Pharmacother 30: 20-26.

21. Christensen LK, Hansen J, Kristensen M (1991) Suiphaphenazole-induced hypoglycaemic attacks in tolbutamide-treated diabetics. Lancet 2: 1298-1301.

22. Kivisto KT, Neuvonen PJ (1991) Effect of magnesium hydroxide on the absorption and efficacy of tolbutamide and chlorpropamide. Eur $\mathrm{J}$ clin Pharmacol 42: 675-680.

23. Ben-Ami H, Nagachandran P, Mendelson A, Edoute $Y$ (1999) Drug-induced hypoglycemic coma in 102 diabetic patients. Arch Intern Med 159: 281-284.

24. Nelson KM, Reiber G, Boyko EJ, Nhanes III (2002) Diet and exercise among adults with type 2 diabetes: findings from the third national health and nutritional examination survey [NHANES III]. Diabetes Care 25: 1722-1728.

25. Huang CL, Wu SC, Jeng CY, Lin LC (2004) The efficacy of a home-based nursing program in diabetic control of elderly people with diabetes mellitus living alone. Public Health Nurs 21: 49-56.

26. Hurley CC, Shea CA (1992) Self-efficacy: strategy for enhancing diabetes selfcare. The Diabetes Educ 18:146-150.

27. Aljasem LI, Peyrot M, Wissow L, Rubin RR (2001) The impact of barriers and self-efficacy on self-care behaviors in type 2 diabetes. Diabetes Educ 27: 393404.

28. Burns N, Grove SK (2001) The practice of nursing research-conduct, critique \& utilization. Philadelphia: WB Saunders Companey.

29. William K, Bond M (2002) The role of self-efficacy, courage, outcome expectance and social support in self-care behaviors of diabetes. Psychology, Health and Medicine 7: 127-141.

30. Diabetes Control and Complications Trial Research Group (1993) The effect of intensive treatment of diabetes on the development and progression of longterm complications in insulin-dependent diabetes mellitus. New Engl J Med 329: 977-986.

31. Ohkubo Y, Kishikawa H, Araki E, Myata T, Isami S, et al. (1995) Intensive insulin therapy prevents the progression of diabetic microvascular complications in
Japanese patients with non insulin dependent diabetes mellitus: a randomized prospective 6-year study. Diabetes Res Clin Pract 28: 103-117.

32. Swift CS, Armstrong JE, Berman KA, Cambell RK, Pond-Smith D (1995) Attitudes and beliefs about exercise among persons with non-insulin dependent diabetes. Diabetes Educ 21: 523-540.

33. Polit DF, Hungler BP (2004) Nursing Research: Principle and Methods (7thedn). Philadelphia: Lippincott Williams \& Wilkins.

34. Gerich JE, Odawara M, Terauchi Y (2007) The rationale for paired pre- and postprandial self-monitoring of blood glucose: the role of glycemic variability in micro- and macrovascular risk. Curr Med Res Opin. 23: 1791-1798.

35. Bergenstal RM, Gavin JR, Global Consensus conference on Glucose monitoring panel (2005) The role of self monitoring of blood glucose in the care of people with diabetes: report of global consensus conference. Am J Med 118: 1S-6S.

36. Renard E (2005) Monitoring glycaemic control: the importance of selfmonitoring of blood glucose. The Am J Med 118: 12S-19S.

37. Tan MY, Magarey J (2008) Self-care practices of Malaysian adults with diabetes and sub-optimal glycaemic control. Patient Educ Couns 72: 252-267.

38. Mastura I, Mimi O, Piterman L, Teng CL, Wijesinha S (2007) Self-monitoring of blood glucose among diabetes patients attending government health clinics. Med J Malaysia 62: 147-151.

39. Chee SS, Zawiah H, Ismail MN, Ng KK (1996) Anthropometry, dietary patterns and nutrients intakes of Malaysian estate workers. Malaysian Journal of Nutrition 2: 112-126

40. Ismail IS, Nazaimoon W, Mohamad W, Letchuman R, Hew FL, et al. (2001) Ethnicity and glycaemic control are major determinants of diabetic dyslipidaemia in Malaysia. Diabet Med 18: 501-508.

41. Pahor M, Psaty BM, Alderman MH, Applegate WB, Williamson JD, et al. (2000) Therapeutic benefits of ACE inhibitors and other antihypertensive drugs in patients with type 2 diabetes. Diabetes Care 23: 888-892.

42. Lovel IH (2003) Angiotensin converting enzyme inhibitors in normotensive diabetic patients with microalbuininuria. Oxford: Update Software.

43. Samuel-Hodge CD, Fernandez LM, Henrfquez-Roldan CF, Johnston LF Keyserling TC (2004) A comparison of self-reported energy intake with total energy expenditure estimated by accelerometer and basal metabolic rate in African-American women with Type 2 diabetes. Diabetes Care 27: 663-669.

44. Subar AF, Kipnis V, Troiano RP, Midthune D, Schoeller DA, et al. (2003) Using intake biomarkers to evaluate the extent of dietary misreporting in a large sample of adults: the OPEN study. Am J Epidemiol 158: 1-13.

45. Boehm S, Schlenk EA, Funnell MM, Powers H, Ronis DL (1997) Predictors of adherence to nutrition recommendations in people with non-insulin-dependent diabetes mellitus. Diabetes Educ 23: 157-165.

46. Travis T (1997) Patient perceptions of factors that affect adherence to dietary regimens for diabetes mellitus. Diabetes Educ 23: 152-156

47. Tee ES, Mohd IN, Mohd NA, Idris K (1997) Nutrient composition of Malaysian foods. $4^{\text {th }}$ ed. Kuala Lumpur: Smart Print \& Stationer Sdn. Bhd.

48. Wen LK, Parchman ML, Shepherd MD (2004) Family support and diet barriers among older Hispanic adults with type 2 diabetes. Fam Med 36: 423-430.

49. Suriah AR, Zainorni M, Shafawi S, Mimie SS, Zarina N, et al. (1996) Nutrient intake among elderly in southern Peninsular Malaysia. Malaysian Journal of Nutrition 2: 11-19.

50. Bantle JP, Wylie-Rosett J, Albright AL, Apovian CM, Clark NG, et al. (2006) Nutrition recommendations and interventions for diabetes--2006: a position statement of the American Diabetes Association. Diabetes care 29: 2140-2157.

51. Suzana S (2000) Food intake and habits of rural elderly Malays. Asia Pacific Journal of clinical nutrition 9: 122-129.

52. Malaysian Dietician's Association (2005) Medical Nutrition therapy Guidelines for Type 2 Diabetes. Kuala Lumpur: Graphic Expediton

53. Nutrition sub-committee of the diabetes Care Advisory Committee of Diabetes UK (2003) The Dietician challenge: the implementation of nutritional advice fo people with diabetes. Journal of Human Nutrition Dietetic 16: 421-452.

54. Stein CJ, Colditz GA (2004) The epidemic of obesity. J Clin Endocrinol Metab 89: $2522-2525$ 
Citation: Gillani SW, Syed Sulaiman SA, Baig M, Sari YO, Sheikh Ghadzi SM, et al. (2013) Effect of Pharmacist Intervention to Self-Care Practices among Diabetes Patients. J Diabetes Metab 4: 252. doi:10.4172/2155-6156.1000252

55. Hadaegh F, Ghasemi A, Padyab M, Tohidi M, Azizi F (2008) The metabolic syndrome and incident diabetes: assessment of alternative definitions of the metabolic syndrome in an Iranian urban population. Diabetes Res Clin Prac 80: 328-334.

56. Dalgård C, Thurøe A, Haastrup B, Haghfelt T, Stender S (2001) Saturated fat intake is reduced in patients with ischemic heart disease 1 year after comprehensive counseling but not after brief counseling. J Am Diet Assoc 101: $1420-1429$.

57. Christian JG, Bessesen DH, Byers TE, Christian KK, Goldstein MG, et al. (2008) Clinic based support to help overweight patients with type 2 diabetes increase physical activity and loss weight. Arch Intern Med 168: 141-146.

58. Heshka S, Greenway F, Anderson JW, Atkinson RL, Hill JO, et al. (2000) Selfhelp weight loss versus a structured commercial program after 26 week: a randomized controlled study. Am J Med 109: 282-287.

59. Farmer J (2008) Diabetic Dyslipidemia and atherscierosis: evidence from clinical trials. Curr Diab Rep 8: 71-77.

60. Cefalu WT (2008) Diabetic dyslipidemia and the metabolic syndrome. Diabetes \& Metabolic Syndrome Clinical research and Reviews 2: 208-222.

61. Plosker G, Faulds D (1999) Troglitazone: a review of its use in the management of type 2 diabetes mellitus. Drugs 57: 409-438.

62. Caldwell MA, Peters Kj, Dracup KA (2005) A simplified education program improves knowledge, self-care behavior, and disease severity in heart failure patients in rural setting. Am Heart J 150: 983.

63. Vincent D, Pasvogel A, Barrera L (2007) A feasibility study of a culturally tailored diabetes intervention for Mexican Americans. Biol Res Nurs 9: 130-141.

64. Tan SL, Yong LS, Wan S, Wong ML (1997) Patient education in the management of diabetes mellitus. Singapore Med J 38: 156-160.

65. Ministry of Health Malaysia (2006) Non-communicable Disease Risk factors in Malaysia Disease Control Division (NCD). Malaysian NCD Surveillence: 1-115.

66. Hawthone K (2001) Effect of culturally appropriate health education on glycaemic control and knowledge of diabetes in British Pakistani Women with type 2 diabetes mellitus. Health Educ Res 16: 373-381.

67. Middlekoop B, van der Wal G (2004) Culture-specific diabetes care for Surinam South Asians with a low socio-economic position: who benefits? Patient Educ couns 53: 353-358.

68. Kulzer B, Hermanns n, Reinecker H, Haak T (2007) Effects of self-management training in type 2 diabetes: a randomized prospective trial. Diabet Med 24: 415423

69. Clark M, Hampson SE, Avery L, Simpson R (2004) Effects of a tailored lifestyle self-management intervention in patients with type 2 diabetes. $\mathrm{Br} \mathrm{J}$ Health Psychol 9: 365-379.

70. Brown S (1992) Meta-analysis of diabetes patient education research: variations in intervention effects across studies. Res Nurs Health 15: 409-419.

71. Deakin T, Cade J, Williams R, Greenwood D (2006) Structured patien education: the diabetes X-PERT programme makes a difference. Diabet Med 23: $944-954$
72. Raji A, Gomes H, Beard JO, MacDonald P, Conlin PR (2002) A randomized tria comparing intensive and passive education in patient with diabetes mellitus. Arch Intern Med 162: 1301-1304.

73. Clement S (1995) Diabetes Self-care management education. Diabetes Care 18: $1204-1214$

74. Elasy T, Ellis S, Brown A, Pichert J (2001) A taxanomy of diabetes educationa intervention. Pateint educ Couns 43: 121-127.

75. Rubin RR (2005) Adherence to pharmacologic therapy in patients with type 2 diabetes mellitus. The Am J Med 118: 27S-34S.

76. Evans J, Newton R, Ruta D, MacDonald T, Stevenson R, et al. (1999) Frequency of blood glucose monitoring in relation to glycaemic control: Observational study with diabetes database. BMJ 319: 83-86.

77. Stipanovic AR (2003) The effects of diabetes education on self-efficacy and self-care of adults with type 2 diabetes [Doctrol Dissertation]. Manitoba: The Univeristy of Manitoba.

78. Rhee MK, Slocum W, Ziemer DC, Culler SD, Cook CB, et al. (2005) Patient adherence improves glycaemic control. Diabetes Educ 31: 240-250.

79. Murata G, Shah J, Duckworth W, Wendel C, Mohler M, et al. (2004) Food frequency questionnaire results correlate with metabolic control in insulinrelated veterans with type 2 diabetes: The diabetes outcomes in Veterans study. J Am Diet Assoc 12: 1816-1826.

80. Krass I, Armour CL, Mitchell B, Brilliant M, Dienaar R, et al. (2007) The pharmacy Diabetes Care Program: assessment of a community pharmacy diabetes service model in Australia. Diabet Med 24: 677-683.

81. Suppapitiporn S, Chindavijak B, Onsanit S (2005) Effects of diabetes drug counseling by the pharmacist, diabetic disease booklet and special medication containers on glycaemic control of type 2 diabetes mellitus: a randomized controlled trial. J Med Assoc Thai 88: S134-S141.

82. Welschen LM, Bloemendal E, Nijpels G, Dekker J, Heine RJ, et al. (2005) Selfmonitoring of blood glucose in patients with type 2 diabetes who are not using insulin. Cochrane Database Sys Rev: CD005060.

83. Wubben DP, Vivan EM (2007) Effects of outpatient interventions by the pharmacists on patient outcomes in adults with diabetes mellitus. Diabetes 56 A316.

84. Arcury TA, Preisser JS, Gesler WM, Powers JM (2005) Access to transportation and health care utilization in a rural region. J Rural Health 21: 31-38.

85. Strauss K, MacLean C, Troy A, Littenberg B (2006) Driving distance as a barrier to glycaemic control in diabetes. J Gen Intern Med 21: 378-380.

86. Westaway MS, Seager JR, Rheeder P, Van Zyl DG (2005) The effects of socia support on health, well being and management of diabetes mellitus: A black South African Perspective. Ethn Health 10: 73-89.

87. Khoo KL, Liew YM, Tan H, Sambhi JS, Hatijah BA (1999) Patient's knowledge and attitude towards treatment and control of hypertension: a nation-wide telephone survey conducted in Malaysia. Med J Malaysia 54: 37-46.

88. Leong KC, Chen WS, Leong KW, Mastura I, Mimi O, et al. (2006) The use of text messaging to improve attendance in primary care: a randomized controlled trial. Fam Pract 23: 699-705. 